\title{
INTERFERÊNCIA DO USO E OCUPAÇÃO DO SOLO NA QUALIDADE DA ÁGUA EM BACIA HIDROGRÁFICA ÇOM DISPONIBILIDADE HÍDRICA CRÍTICA
}

\author{
INTERFERENCE OF SOIL USE AND OCCUPATION IN WATER QUALITY IN A WATERSHED \\ WITH CRITICAL WATER AVAILABILITY
}

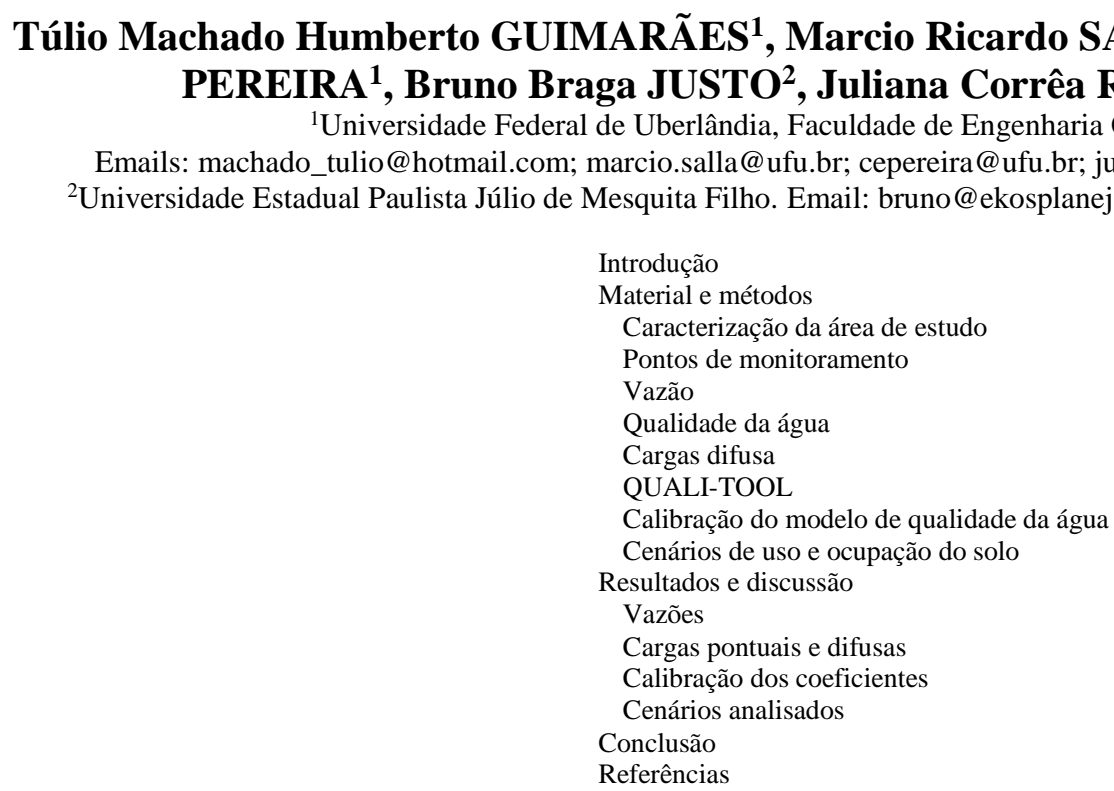

\begin{abstract}
RESUMO - A vazão máxima superficial outorgada na bacia hidrográfica do Ribeirão do Salitre, Triângulo Mineiro, ultrapassa o máximo permitido pela legislação vigente e aloca, na cabeceira do principal tributário, a cava de uma mina de fosfato. Procedeu-se, no período seco e chuvoso, a calibração do modelo matemático de autodepuração utilizando a ferramenta QUALI-TOOL. Na sequência avaliou-se a interferência do uso e ocupação do solo na qualidade da água em diferentes cenários utilizando o modelo MQUAL para estimar as cargas poluentes. Os cenários avaliaram o avanço das atividades de mineração, agricultura e pecuária sobre o solo natural. Baseado na Resolução CONAMA 357:2005, para rio de classe 2, a concentração de nitrato ficou abaixo do máximo permitido em todos os cenários, ou seja, $10 \mathrm{mg} / \mathrm{L}$. O nitrogênio amoniacal apresentou concentração elevada apenas no cenário em que considerou $80 \%$ de área total ocupada pela agricultura, com valores superiores a 3,7 mg/L. Em todos os cenários, os parâmetros DBO, fósforo total e Escherichia Coli mantiveram-se acima do máximo permitido pela resolução que são 5,0 mg/L, 0,05 mg/L, 1000 NMP/100mL, respectivamente. $\mathrm{O}$ estudo retrata a importância do planejamento e gestão de recursos hídricos na preservação da qualidade da água superficial.
\end{abstract}

Palavras chave: Uso e ocupação do solo; Qualidade da água; Ribeirão do Salitre; QUALI-TOOL; MQUAL.

\begin{abstract}
The maximum surface flow in Ribeirão do Salitre, Triângulo Mineiro, exceeds the maximum allowed by the current legislation and allocates, at the head of the main tributary, the pit of a phosphate mine. The calibration of the mathematical model of self-purification using the QUALI-TOOL tool was carried out in the dry and rainy period. The influence of soil use and occupation on water quality in different scenarios was evaluated using the MQUAL model to estimate the pollutant loads. The scenarios evaluated the progress of mining, agriculture and livestock activities on the natural soil. Based on the CONAMA Resolution 357: 2005, for class 2 river, the nitrate concentration was below the maximum allowed in all scenarios, that is, $10 \mathrm{mg} / \mathrm{L}$. The ammoniacal nitrogen presented a high concentration only in the scenario in which it was considered $80 \%$ of the total area occupied by agriculture, with values higher than $3.7 \mathrm{mg} / \mathrm{L}$. In all scenarios, the parameters BOD, total phosphorus and Escherichia Coli remained above the maximum allowed by the resolution, which are $5.0 \mathrm{mg} / \mathrm{L}, 0.05 \mathrm{mg} / \mathrm{L}, 1000 \mathrm{NMP} / 100 \mathrm{~mL}$, respectively. The study portrays the importance of planning and of management of water resources in the preservation of surface water quality.
\end{abstract}

Keywords: Land use and occupation; Water quality; Ribeirão do Salitre; QUALI-TOOL; MQUAL.

\section{INTRODUÇÃO}

O crescimento urbano no Brasil tem sido intensificado desde o ano de 1960, quando os trabalhadores rurais iniciaram a migração para as cidades em busca de oportunidades de emprego com melhores remunerações, infraestrutura, serviços (educação, saúde, transporte) e qualidade de ensino (Cunha, 2005). Entretanto, as cidades não suportaram este crescimento de 
forma planejada e com a infraestrutura básica necessária a todos. Sendo assim, surgiram grandes zonas periféricas, as quais necessitam de investimentos para que todos tenham acesso à saúde, educação e lazer. Com o acentuado crescimento urbano, a ampliação do setor industrial e a falta de planejamento, o despejo de efluente sem tratamento nos cursos de água é intensificado.

Além disso, com o término da Segunda Guerra Mundial, os agrotóxicos passaram a ser utilizados como defensivos agrícolas (Sanágua, 2017). O uso de agrotóxicos em nosso país ocorreu de forma mais frequente por volta da década de 60, quando o governo brasileiro impôs que financiamento bancário destinado à compra de semente somente seria realizado para quem fizesse também a compra de adubo e agrotóxico. Houve, com isso, o aumento da contaminação no meio ambiente.

A fim de proporcionar o enriquecimento do solo, a indústria química criou os fertilizantes. Estes são nutrientes minerais, naturais ou manufaturados, que contêm substâncias essenciais para o desenvolvimento normal das plantas. Os nutrientes que estão presentes em grande quantidade nos fertilizantes são o nitrogênio, fósforo e potássio (Isherwood, 2010). Com a ampla utilização de fertilizantes nas plantações, é comum encontrar concentrações elevadas de nitrogênio e fósforo nos cursos de água, carreados por meio do processo de lixiviação.

Os cursos de água possuem limitações quanto às cargas poluentes que recebem, sendo assim, necessitam de espaço e tempo para que, por meio de processos naturais, possam reestabelecer o equilíbrio na qualidade da água. Com o objetivo de analisar e propor alternativas de controle, as ferramentas computacionais possibilitam a modelagem matemática de qualidade da água em curso de água natural.

Segundo Ferreira (2014), o gerenciamento dos recursos hídricos tem sido elemento de discussão na comunidade científica e política, sendo observados conflitos de uso em locais em que a vazão se torna restritiva durante um período do ano. Nesse contexto, a sub-bacia do Ribeirão do Salitre exemplifica as questões abordadas por se tratar de uma bacia crítica, quali e quantitativamente, em função da grande quantidade de outorgas para irrigantes, principalmente nas proximidades de cabeceira na bacia, além de haver uma mineradora de fosfato na cabeceira do principal tributário do Ribeirão do Salitre (Jhunior, 2017).

Em busca do equilíbrio entre demanda, disponibilidade hídrica e qualidade da água no Ribeirão do Salitre, este estudo avaliou a capacidade de autodepuração no curso de água frente aos diversos cenários de uso e ocupação do solo.

\section{MATERIAL E MÉTODOS}

\section{Caracterização da área de estudo}

A sub-bacia do Ribeirão do Salitre está inserida na bacia hidrográfica do rio Araguari, Minas Gerais, entre as coordenadas 7907898,46 e 7868520,77 UTM Sul e 291350,15 e 323847,13 UTM Leste. Possui uma área de aproximadamente $600 \mathrm{~km}^{2}$, onde $63,5 \%$ desta área pertence ao munícipio de Patrocínio e 36,5\% ao município de Serra do Salitre. Os córregos do Bebedouro e do Areia são os principais tributários, conforme ilustra a figura 1 . O comprimento total da hidrografia na sub-bacia é de 597,7 km, enquanto o comprimento do ribeirão do Salitre é de 74 km (Faria, 2011).

De acordo com Jhunior (2017), dentre as dezoito sub-bacias existentes na bacia do rio Araguari, a sub-bacia do Ribeirão do Salitre é uma das sub-bacias com disponibilidade hídrica crítica. A vazão máxima superficial outorgada ultrapassa o máximo permitido pela legislação vigente e ainda

possui, na cabeceira do principal tributário, uma cava de mina de fosfato e grande quantidade de outorgas para irrigação. A Figura 1 apresenta também a vazão outorgada frente ao máximo permitido (50\% da $\mathrm{Q}_{7,10}$ ) na sub-bacia do Ribeirão do Salitre em período de estiagem.

Esta região do Triângulo Mineiro se destaca por atividades econômicas ligadas à mineração, agricultura (principalmente o cultivo de café e hortaliças), agropecuária, agroindústrias e turismo (CBH - Araguari, 2017).

Possui altitude média de 977 metros, temperatura média anual de $21,4^{\circ} \mathrm{C}$ e pluviosidade média anual de $1507 \mathrm{~mm}$ (Climate-Data.Org, 2018). Salitre de Minas, que é distrito do município de Patrocínio e tem uma população de aproximadamente 4000 habitantes (IBGE, 2018), lança seu efluente sanitário tratado diretamente no médio curso do Ribeirão do Salitre (Figura 1). 

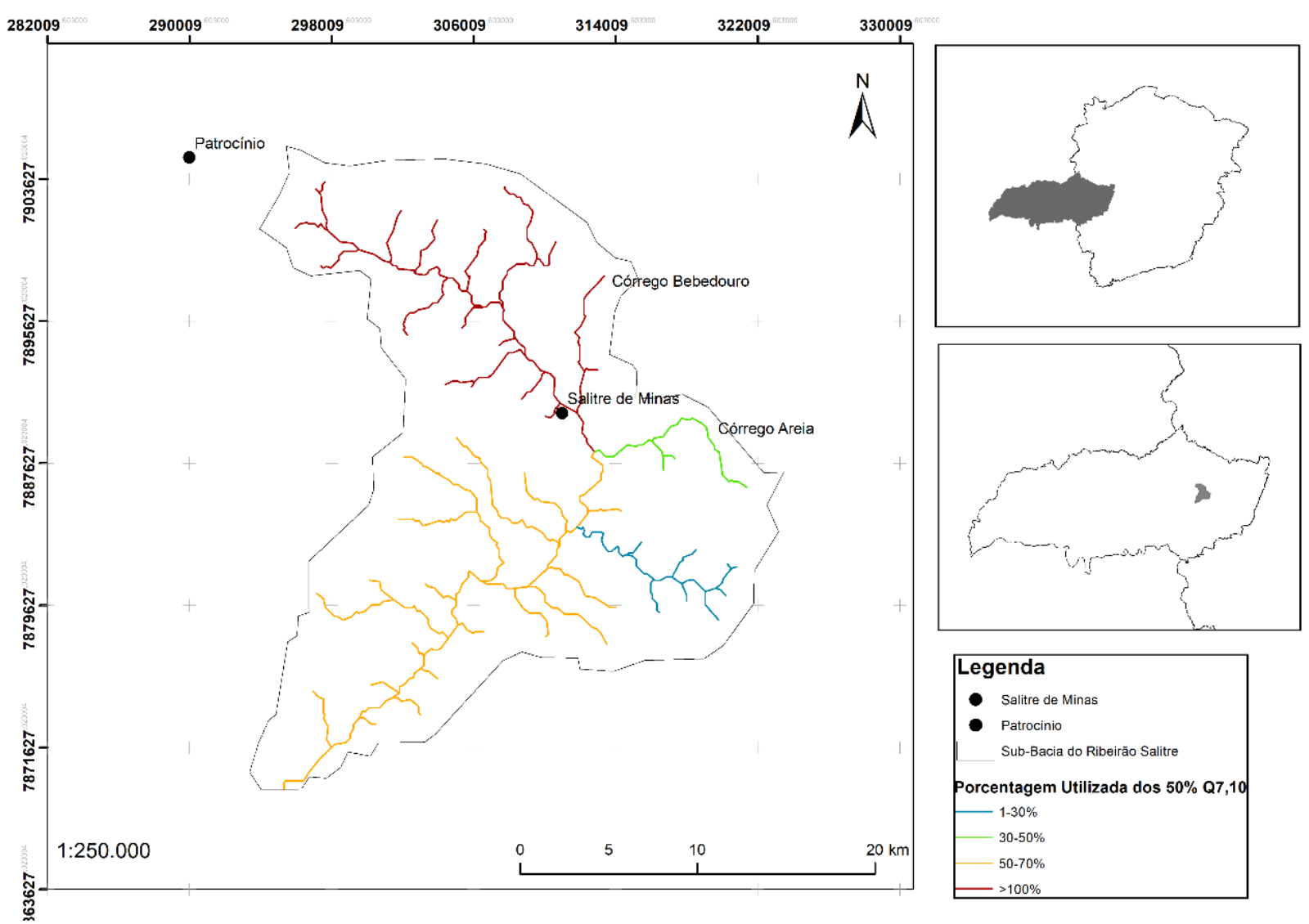

Figura 1 - Hidrografia, subdivisão, pontos de monitoramento e delimitação da vazão outorgada frente ao máximo permitido da $\mathrm{Q}_{7,10}$ na sub-bacia do Ribeirão do Salitre.

\section{Pontos de monitoramento}

A modelagem matemática da qualidade da água em um corpo hídrico, independente da ferramenta computacional escolhida, necessita de dados fluviométricos e de qualidade da água monitorados. Os dados fluviométricos e de qualidade da água para a cabeceira e os tributários são utilizados como dados de entrada, enquanto os dados de qualidade da água ao longo do curso de água de interesse são utilizados na calibração do modelo. Também, o monitoramento de vazão ao longo do curso de água de interesse auxilia na estimativa da vazão em tributários sem monitoramento.

Neste estudo foram utilizados cinco pontos de monitoramento, cuja localização georreferenciada é ilustrada na Figura 2. Como dados de entrada foram considerados os pontos 1,4 e 5 , enquanto os pontos 2 e 3 foram utilizados na calibração do modelo.

O ponto 2 foi utilizado também na estimativa da vazão, pelo método de descarga específica, em tributários sem monitoramento fluviométrico. $\mathrm{O}$ estudo considerou o lançamento de efluente tratado gerado no distrito de Salitre de Minas A confluência do Córrego Bebedouro com o Ribeirão do Salitre está situada a 50 metros a montante do ponto 2. A estação de tratamento de esgoto (ETE) do distrito de Salitre de Minas se localiza a 3.886 metros a jusante do ponto 1 , além do que o córrego Areia está situado 50 metros a montante do ponto 3 (Figura 2).

\section{Vazão}

O monitoramento fluviométrico nos pontos 1,4 e 5 foi realizado por meio de molinete fluviométrico, enquanto no ponto 2 foi utilizado o equipamento ADCP - Acoustic Doppler Current Profiler. Foram realizadas duas campanhas no período de estiagem (agosto e setembro de 2017) e duas campanhas no período chuvoso (novembro e dezembro de 2017).

A vazão de efluente sanitário gerada no distrito Salitre de Minas foi estimada e considerada fixa nos períodos de estiagem e chuvoso. Na estimativa da vazão foi considerada a população de 4.000 habitantes (PMP, 2017), consumo diário de 150 L/hab (Von Sperling, 2005) e coeficiente de retorno de 0,8 (Von Sperling, 2005).

Para os córregos sem nome (sem monitoramento fluviométrico) e para as entradas difusas, a vazão foi estimada a partir do método de descarga específica. 


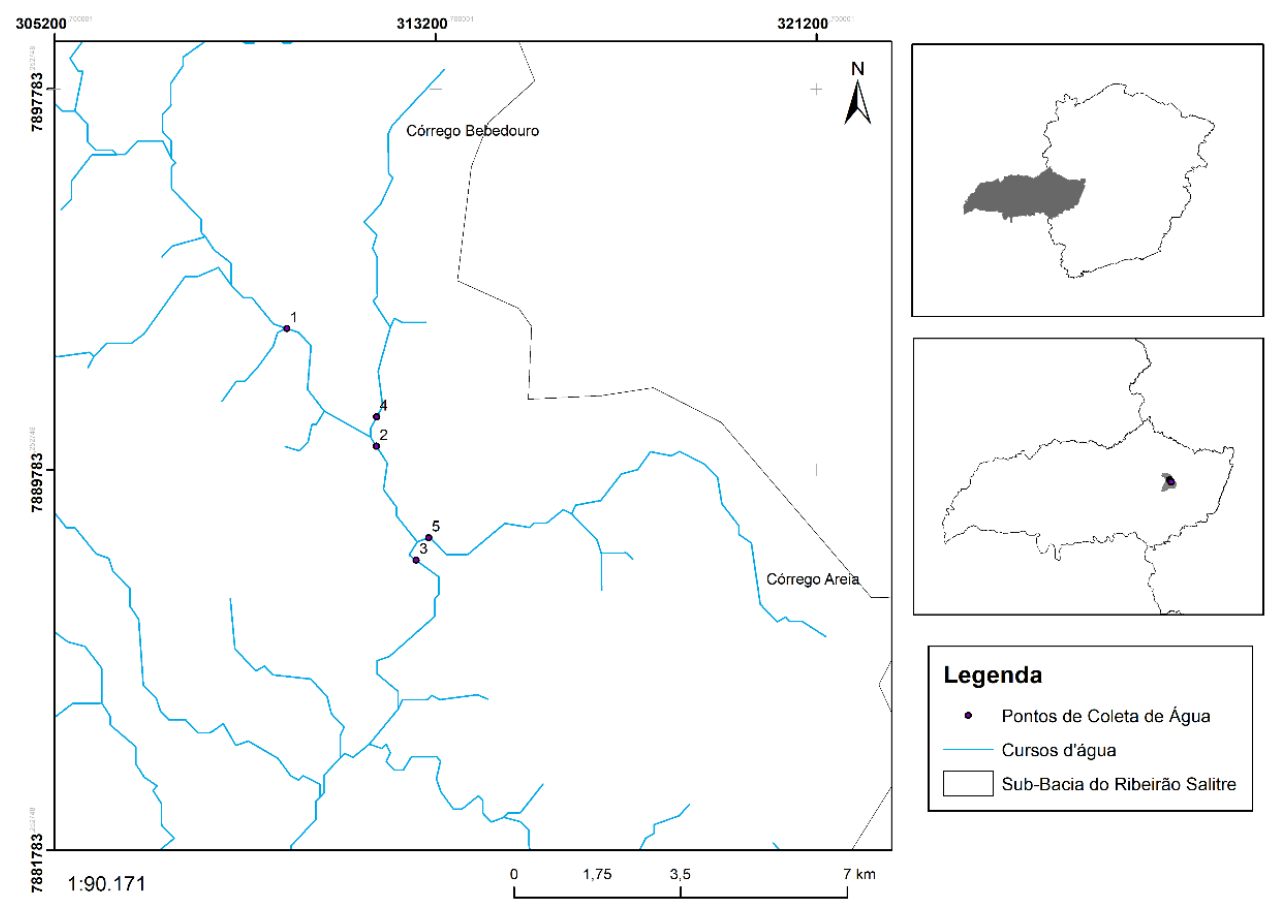

Figura 2 - Localização dos pontos de monitoramento no alto curso do ribeirão do Salitre.

\section{Qualidade da água}

O monitoramento de qualidade da água foi realizado nos pontos 1 a 5. Os parâmetros analisados foram oxigênio dissolvido, demanda bioquímica de oxigênio, nitrogênio amoniacal, nitrato, temperatura, fósforo total e Escherichia Coli. Os ensaios foram realizados em duplicata seguindo as diretrizes da NBR 9898:1987. Foram realizadas duas campanhas no período de estiagem (agosto e setembro de 2017) e duas campanhas no período chuvoso (novembro e dezembro de 2017).

$\mathrm{Na}$ estimativa dos parâmetros de qualidade do efluente sanitário produzido pelo distrito Salitre de Minas, foram adotadas concentrações recomendadas por Von Sperling (2014). Para os córregos sem nome (sem monitoramento) e para as entradas difusas, a concentração foi estimada a partir da divisão entre a carga poluente obtida pelo método MQUAL (item seguinte) e a vazão obtida por descarga específica.

\section{Cargas difusas}

O modelo matemático de correlação uso do solo/qualidade da água - MQUAL 1.6 (SMA, 2010) foi utilizado na estimativa da carga poluente afluente ao ribeirão Salitre no período de estiagem (agosto e setembro de 2017) e chuvoso (novembro e dezembro de 2017), além da utilização nos cenários de uso e ocupação do solo descritos na sequência. Este modelo traz boa aceitação em trabalhos técnicos e científicos (Oliveira \& Sardinha, 2014; Moruzzi, 2012). A tabela 1 apresenta os coeficientes de geração de carga (em $\mathrm{kg} / \mathrm{km}^{2}$.dia) para cada tipo de uso e ocupação do solo.

Tabela 1 - Coeficientes de geração de cargas $\left(\mathrm{kg} / \mathrm{km}^{2}\right.$.dia)

\begin{tabular}{l|c|c|c|c}
\hline \multicolumn{1}{c|}{ Fonte } & $\mathbf{P}_{\mathbf{T}}$ & $\mathbf{N}_{\mathbf{T}}$ & DBO & E.coli \\
\hline Atividade Agropecuária & 0,050 & 0,900 & 2,250 & $10^{9}$ \\
\hline Agricultura & 0,346 & 2,950 & 7,315 & $10^{11}$ \\
\hline Mata/ reflorestamento & 0,039 & 0,600 & 1,197 & $10^{8}$ \\
\hline Campo/cerrado & 0,028 & 0,500 & 1,064 & $10^{8}$ \\
\hline Atividade industrial & 0,081 & 1,784 & 7,749 & $10^{9}$ \\
\hline Área urbana & 0,135 & 2,548 & 11,070 & $10^{9}$ \\
\hline
\end{tabular}

Fonte: Programa MQUAL 1.6

Uma atividade paralela à aplicação do modelo MQUAL 1.6 é a definição dos usos múltiplos do solo e as suas correspondentes áreas de ocupação. Para isso foi realizado o mapeamento dos principais tipos de uso e cobertura do solo na subbacia do Ribeirão do Salitre por meio da classificação supervisionada de imagens multiespectrais do sensor MSI do satélite Sentinel 2A, obtidas da base de dados do U.S Geological Survey (USGS), correspondentes às cenas T23KKU, T23KKV, T23KLU e T23KLV, com bandas de dez metros de resolução espacial datadas 
de 04 de junho de 2017. Com base nas características da região, as classes de caracterização foram atividades agrícolas, mata/reflorestamento, campo/atividade agropecuária e área de uso industrial (mineração). Por meio da ferramenta computacional QGIS foi possível obter a área em função do tipo e ocupação do solo na sub-bacia.

\section{QUALI-TOOL}

A ferramenta computacional de uso livre QUALI-TOOL permite a simulação da qualidade da água em ambiente lótico, em escala local ou em escala de bacia hidrográfica, com até quinze tributários afluentes ao rio principal. Esta ferramenta reproduz os processos físicos, químicos e biológicos, considerando entradas pontuais e difusas de cargas poluidoras e retiradas pontuais consuntivas e não consuntivas (Magalhães et al., 2017a, b).

A ferramenta faz o balanço hídrico em cada trecho discretizado após a introdução das vazões de entrada (pontuais e difusas) e das vazões de saída pontuais. A determinação do nível líquido ocorre por meio da equação de Manning, considerando o escoamento permanente e uniforme. Para isso, alguns dados geométricos são requeridos, tais como: largura de fundo do canal e declividades do talude esquerdo e direito. A ferramenta determina a declividade longitudinal a partir de pontos georreferenciados que descrevem o traçado do curso de água. Quando o rio principal se encontra com um tributário ou com uma carga efluente, a concentração de mistura é calculada por meio da Equação 1.

$$
C_{M}=\left(Q_{P} \times C_{P}+Q_{E} \times C_{E}\right) /\left(Q_{P}+Q_{E}\right)
$$

Na qual: $C_{M}$ é a concentração da mistura (mg/L); $C_{P}$ é a concentração do rio principal à montante da mistura $(\mathrm{mg} / \mathrm{L}) ; Q_{P}$ é a vazão do rio principal a montante da mistura ( $\left.\mathrm{m}^{3} / \mathrm{s}\right) ; C_{E}$ é a concentração do tributário ou da carga efluente $(\mathrm{mg} / \mathrm{L}) ; Q_{\mathrm{E}}$ é a vazão do tributário ou da carga efluente $\left(\mathrm{m}^{3} / \mathrm{s}\right)$.

A QUALI-TOOL utiliza o método de diferenças finitas para a solução de equações matemáticas, o qual consiste na divisão do domínio em um número finito de pequenas regiões ou trechos de curso de água. A dispersão do parâmetro de qualidade da água ao longo do tempo ou ao longo do curso de água é simulada por meio da equação de difusão-advecção (Equação 2).

$$
d C / d t+u_{i} \times d C / d x_{i}=d / d x_{i} \times\left(D_{i} \times d C / d x_{i}\right) \pm \sum F
$$

$\mathrm{Na}$ qual: $C$ é a concentração do poluente no tempo $\mathrm{t} ; t$ é o tempo decorrido desde a zona de mistura entre o contaminante e o meio líquido (dia); $i$ corresponde às direções $\mathrm{x}, \mathrm{y}$ e $\mathrm{z} ; D$ corresponde ao coeficiente de difusão turbulenta; $u$ componente do vetor velocidade do escoamento; $F$ é o termo fonte-sumidouro.

As representações matemáticas de $F$ para a simulação dos parâmetros $\mathrm{OD}$, DBO, nitrogênio orgânico (NO), nitrogênio amoniacal $\left(\mathrm{NH}_{3}\right)$, nitrato $\left(\mathrm{NO}_{3}\right)$, fósforo total $\left(\mathrm{P}_{\text {total }}\right)$ e coliformes (E.coli) são demonstradas nas equações (3) a (9), respectivamente.
$\Sigma F_{O D}=+k_{2} \times 1,024^{(T-20)} \times\left(O D_{\text {sat }} O D D\right)-k d \times 1,047^{(T-20)} \times D B O-R_{02-a m o n i a} \times f_{\text {nitr }} \times k_{\text {an }} \times 1,080$
$\Sigma F_{D B O}=-k_{d} \times 1,047^{(T-20)} \times D B O-\left(V S_{M O} / h\right) \times D B O+L_{\text {difuso }} / h$
$\Sigma F_{N O}=-k_{o a} \times 1,047^{(T-20)} \times N_{\text {org }}-\left(V S_{N O} / h\right) \times N_{\text {org }}$
$\Sigma F_{N H 3}=+k_{o a} \times 1,047^{(T-20)} \times N_{\text {org }}-R_{O 2 \text {-amonia }} \times f_{\text {nitr }} \times k_{\text {an }} \times 1,080^{(T-20)} \times N H 3+S_{\text {amônia }} / h$
$\Sigma F_{N O 3-}=+k_{n n} \times 1,047^{(T-20)} \times N O 2-$
$\Sigma F_{\text {Ptotal }}=-k_{P} \times 1,047^{(T-20)} \times P_{\text {total }}-\left(V S_{P} / h\right) \times P_{\text {total }}$
$\Sigma F_{\text {E.coli }}=-k_{b} \times 1,070^{(T-20)} \times$ E.coli

Nas equações (3) a (9): $O D$ é a concentração de oxigênio dissolvido, em $\mathrm{mg} / \mathrm{L} ; O D_{\text {sat }}$ é a concentração de saturação de oxigênio dissolvido, em $\mathrm{mg} / \mathrm{L} ; D B O$ é a demanda bioquímica de oxigênio, em $\mathrm{mg} / \mathrm{L} ; N O$ é a concentração de nitrogênio orgânico, em $\mathrm{mg} / \mathrm{L} ; \quad N H 3$ é a concentração de nitrogênio amoniacal, em $\mathrm{mg} / \mathrm{L}$; NO3 - é a concentração de nitrato, em $\mathrm{mg} / \mathrm{L} ; P_{\text {total }}$ é a concentração de fósforo total (mg/L); E.coli é a concentração de coliformes, em NMP/100 mL; $k_{2}$ é o coeficiente de reaeração, em $\operatorname{dia}^{-1} ; k_{d}$ é o coeficiente de decomposição da matéria orgânica carbonácea no rio, em dia ${ }^{-1} ; k_{a n}$ é o coeficiente de conversão de amônia em nitrito, em dia $^{-1} ; k_{o a}$ é o coeficiente de conversão de nitrogênio orgânico em amônia, em dia ${ }^{-1} ; k_{n n}$ é o coeficiente de conversão de nitrito em nitrato, em dia $^{-1} ; k_{P}$ representa a constante de degradação do fósforo total $\left(\mathrm{dia}^{-1}\right) ; k_{b}$ é o coeficiente de decaimento de coliforme, em dia ${ }^{-}$ 1; $V S_{M O}$ é a velocidade de sedimentação da matéria orgânica carbonácea, em $\mathrm{m} / \mathrm{dia} ; \quad V S_{N O}$ é a velocidade de sedimentação do nitrogênio 
orgânico, em $\mathrm{m} / \mathrm{dia} ; \quad V S_{P}$ é a velocidade de sedimentação do fósforo total (em $\mathrm{m} / \mathrm{dia}) ; S_{d}$ é a demanda de fundo de oxigênio dissolvido no rio, em $\mathrm{gO}_{2} / \mathrm{m}^{2}$.dia; $L_{\text {difuso }}$ é a carga difusa de DBO, em $\mathrm{g} / \mathrm{m}^{2}$.dia; $S_{\text {amônia }}$ é o ressurgimento de fundo da amônia, em $\mathrm{g} / \mathrm{m}^{2}$.dia; $T$ é a temperatura da água, em ${ }^{\circ} \mathrm{C} ; ~ h$ é a profundidade líquida do rio, em metros; RO2-amonia é o consumo de oxigênio para oxidação da amônia, em $\mathrm{mgO}_{2}$ cons/mgNH3 $3_{\text {oxid; }} f_{\text {nitr }}$ é o fator de nitrificação, adimensional.

\section{Calibração do modelo de qualidade da água}

A calibração dos coeficientes inseridos nas equações (3) a (9) foi feita por tentativa e erro, dentro dos intervalos de referência propostos no manual do usuário da ferramenta QUALI-TOOL. $\mathrm{O}$ processo consistiu em alterar os valores dos

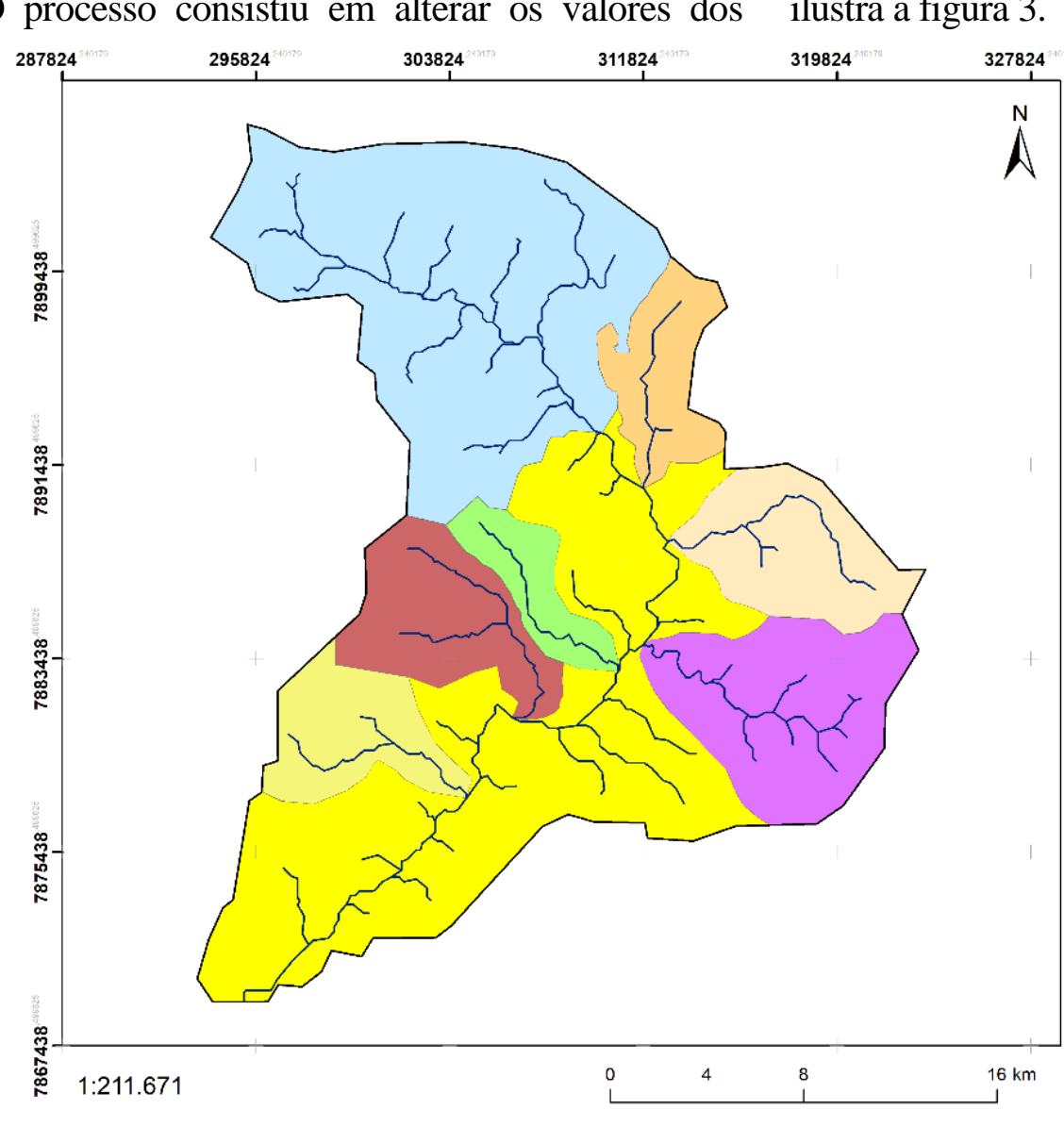

coeficientes de modo que a curva de concentração dos parâmetros se aproximasse ao máximo dos valores obtidos no ponto de monitoramento 2 e 3 (são os pontos ao longo do ribeirão Salitre). O processo de calibração foi feito no alto curso da sub-bacia do Ribeirão do Salitre, adotando-se os coeficientes calibrados para toda a sub-bacia nas análises dos cenários.

\section{Cenários de uso e ocupação do solo}

Após a calibração do modelo foram analisados cenários de interferência de uso e ocupação do solo sobre a qualidade de água ao longo do curso de água.

Para isso, a bacia hidrográfica do Ribeirão do Salitre foi dividida em 8 sub-bacias, conforme ilustra a figura 3 .

Figura 3 - Divisões das sub-bacias para análise do uso e ocupação do solo.

Todo imóvel rural no território brasileiro deve manter uma área com cobertura vegetal nativa a título de Reserva Legal (Brasil, 2012). Especificamente na região da bacia do Ribeirão do Salitre, por não estar inserida na Amazônia Legal, deve-se destinar $20 \%$ de sua área para esta finalidade. Também é obrigatório a manutenção de uma Área de Preservação Permanente (APP), a qual é uma área protegida, coberta ou não por vegetação nativa, que tem como função ambiental a preservação dos recursos hídricos e biodiversidade. No caso do Ribeirão do Salitre, o qual apresentou em todos os meses de coleta de água largura inferior a 10 metros, é preciso garantir 30 metros de faixas marginais. Baseado nesses limites, encontrou-se uma área mínima de 123,84 $\mathrm{km}^{2}$ para mata na região da bacia do Ribeirão do Salitre. Também, em todos os cenários analisados adotou-se constante a área urbana, uma vez que nesta região encontra-se o distrito de Salitre de Minas.

A área total da sub-bacia do Ribeirão do Salitre, 
de aproximadamente $600 \mathrm{~km}^{2}$, é atualmente constituída por $38,5 \%$ de agropecuária, $26,3 \%$ de agricultura, $17,8 \%$ de mata/reflorestamento, $16,8 \%$ de campo/cerrado, $0,4 \%$ de atividade industrial/mineração e $0,2 \%$ de área urbana. A tabela 2 traz as áreas consideradas $\left(\mathrm{em} \mathrm{km}^{2}\right)$ de uso e ocupação do solo para as análises dos seis cenários.

Tabela 2 - Áreas (em km² e \% da área) de uso e ocupação do solo para os cenários.

\begin{tabular}{c|c|c|c|c|c|c}
\hline \multirow{2}{*}{ Cenário } & $\begin{array}{c}\text { Atividade } \\
\text { agropecuária }\end{array}$ & Agricultura & $\begin{array}{c}\text { Mata/ } \\
\text { Reflorestamento }\end{array}$ & $\begin{array}{c}\text { Campo/ } \\
\text { cerrado }\end{array}$ & $\begin{array}{c}\text { Atividade industrial/ } \\
\text { mineração }\end{array}$ & $\begin{array}{c}\text { Área } \\
\text { urbana }\end{array}$ \\
\hline \multirow{2}{*}{$\mathbf{1}$} & 221,55 & 151,59 & 123,84 & 96,68 & 3,01 & 1,02 \\
\cline { 2 - 7 } & $37,07 \%$ & $25,36 \%$ & $20,72 \%$ & $16,18 \%$ & $0,50 \%$ & $0,17 \%$ \\
\hline \multirow{2}{*}{$\mathbf{2}$} & 221,20 & 151,35 & 123,84 & 96,53 & 3,76 & 1,02 \\
\cline { 2 - 7 } & $37,01 \%$ & $25,32 \%$ & $20,72 \%$ & $16,15 \%$ & $0,63 \%$ & $0,17 \%$ \\
\hline \multirow{3}{*}{$\mathbf{3}$} & 220,61 & 150,95 & 123,84 & 96,27 & 5,01 & 1,02 \\
\cline { 2 - 7 } & $36,91 \%$ & $25,25 \%$ & $20,72 \%$ & $16,11 \%$ & $0,84 \%$ & 1,02 \\
\hline \multirow{3}{*}{$\mathbf{4}$} & 327,48 & 140,35 & 123,84 & 0,00 & 5,01 & $0,17 \%$ \\
\cline { 2 - 7 } & $54,79 \%$ & $23,48 \%$ & $20,72 \%$ & $0,00 \%$ & $0,84 \%$ & 1,02 \\
\hline \multirow{2}{*}{$\mathbf{6}$} & 140,35 & 327,48 & 123,84 & 0,00 & 5,01 & $0,17 \%$ \\
\cline { 2 - 7 } & $23,48 \%$ & $54,79 \%$ & $20,72 \%$ & $0,00 \%$ & $0,84 \%$ & 1,02 \\
\hline
\end{tabular}

Nos três primeiros cenários foram mantidas as proporções de atividade agropecuária, agrícola e campo/cerrado, aumentando gradualmente a atividade industrial (mineração) para que atinja a área máxima a ser explorada nos próximos 20 anos, conforme SUPRAM - TM/AP (2015). Atualmente $\mathrm{a}$ área destinada à mineração é de $2,61 \mathrm{~km}^{2}$, porém a área permitida para exploração é de $5,01 \mathrm{~km}^{2}$ (somatório das áreas destinadas à cava, britagem primária e secundária, pátio de estocagem de minério, espaço de apoio à mina e pilha de estéril). No cenário 1, a área industrial foi de $3,01 \mathrm{~km}^{2}(60 \%$ da máxima permitida); no cenário 2 , de $3,76 \mathrm{~km}^{2}$ (75\% da máxima permitida) e o cenário 3 retrata a máxima área permitida.

Nos cenários 4 e 5 aumentou-se a área industrial (mineradora) para a máxima permitida pelo licenciamento ambiental, o restante foi dividido entre as atividades agropecuárias e agrícolas. No cenário 4 , há a pecuária com $70 \%$ e a agricultura com $30 \%$ da área restante.

Já no cenário 5, tem-se a pecuária com $30 \%$ e a agricultura com $70 \%$ da área restante. Para finalizar, o cenário 6 prevê a condição mais crítica, visto que a área industrial foi a máxima permitida, a de mata e reflorestamento, a mínima exigida por lei, a área urbana constante e as demais áreas destinadas à agricultura.

\section{RESULTADOS E DISCUSSÃO}

\section{Dados de entrada}

A tabela 3 apresenta os dados de entrada, na ferramenta QUALI-TOOL, de vazão e concentração dos parâmetros para as simulações matemáticas (ponto 1, 4 e 5, córrego Bebedouro, córrego Areia, ETE de Salitre de Minas, córregos sem nome e entradas difusas), além da concentração dos parâmetros nos pontos utilizados para a calibração do modelo (pontos 2 e 3).

\section{Balanço hídrico e calibração dos coeficientes}

A figura 4 traz o balanço hídrico, além dos dados medidos em campo nos pontos 2 e 3 e os perfis dos parâmetros de qualidade após o processo de calibração.
De uma forma geral, apesar da reduzida quantidade de dados monitorados, observa-se visualmente que houve uma satisfatória calibração dos coeficientes de reação bioquímica e da velocidade de sedimentação.

Já a tabela 4 traz os coeficientes calibrados. Em função da boa qualidade de água no ribeirão do Salitre, as cargas relacionadas à demanda de fundo de oxigênio dissolvido no rio $\left(S_{d}\right)$ e ao ressurgimento de fundo da amônia ( $S_{\text {amônia }}$ ) foram desconsiderados.

$\mathrm{O}$ valor do coeficiente de reaeração $\mathrm{k}_{2}$ calibrado variou entre $0,50-57,04 \mathrm{dia}^{-1}$, evidenciando que as elevadas vazões no período chuvoso (com elevação da turbulência de 
superfície) ocasionou o aumento deste coeficiente.

Valores similares de $\mathrm{k}_{2}$ entre 0,01 a 62,6 $\mathrm{dia}^{-1}$ foram obtidos por Salla et al. (2014) e Fernandes (2016) no rio Uberabinha, cujo curso de água é afluente do rio Araguari em sua margem esquerda e traz o uso e ocupação do solo e as características hidráulicas do canal natural similares ao ribeirão do Salitre.

Todavia, a literatura da área mostra discrepâncias quanto ao valor de $\mathrm{k}_{2}$ devido, principalmente, às oscilações na turbulência de superfície ocasionadas pela declividade de fundo e aumento de vazão.

Também deve-se salientar que as equações da literatura superestimam este coeficiente, independente da época do ano. Seguem alguns exemplos na discrepância do coeficiente $\mathrm{k}_{2}$ : Ferreira (2014) obteve $\mathrm{k}_{2}$ entre 1,6 a 4,0 $\mathrm{dia}^{-1}$ no rio Uberaba (MG) para uma vazão do rio entre de 2,5 a $5 \mathrm{~m}^{3} / \mathrm{s}$; Já Formentini (2010) alcançou $\mathrm{k}_{2}$ entre 12,7 - 30,3 dia $^{-1}$ no Rio Vacacaí Mirim (RS) para uma vazão do rio entre 0,013 a 3,33 $\mathrm{m}^{3} / \mathrm{s}$; Oliveira Filho (2014) encontrou $\mathrm{k}_{2}$ de 3,44 dia $^{-1}$ Rio Poti (PI) para uma vazão do rio de 5,5 $\mathrm{m}^{3} / \mathrm{s}$.

Cursos de água com vazões reduzidas de 2,19 $\mathrm{m}^{3} / \mathrm{s}$ e $2,3 \mathrm{~m}^{3} / \mathrm{s}$ e baixa declividade de fundo fornecem valores menores de $\mathrm{k}_{2}$, tais como $\mathrm{o}$ intervalo de 0,07 a 0,42 $\mathrm{dia}^{-1}$ obtido por Nunes (2008) no rio Turvo (MG) e 1,05 dia ${ }^{-1}$ obtido por Tonon (2014) no rio Lambari (MG).

O coeficiente de decomposição da matéria orgânica carbonácea $\mathrm{k}_{\mathrm{d}}$ calibrado manteve-se entre 0,12 a $0,18 \mathrm{dia}^{-1}$.

Outros estudos alcançaram valores similares, como 0,21 a 0,80 dia ${ }^{-1}$ em Fernandes (2016), 0,05 a 0,07 $\mathrm{dia}^{-1}$ em Salla et al. (2014), 0,10 a 0,12 $\mathrm{dia}^{-}$ ${ }^{1}$ em Ferreira (2014), 0,16 $\mathrm{dia}^{-1}$ em Tonon (2014), $0,85 \mathrm{dia}^{-1}$ em Oliveira Filho (2014) e 0,12 a 0,24 dia $^{-1}$ em Paula (2011).O coeficiente de conversão de amônia em nitrito $k_{a n}$ manteve-se entre 0,15 a $0,20 \mathrm{dia}^{-1}$ e se encontra dentro do intervalo apresentado por Von Sperling (2014), entre 0,15 a $0,25 \mathrm{dia}^{-1}$, e por Paredes Arquiola et al. (2010), entre 0,01 a $1,0 \mathrm{dia}^{-1}$.

Tabela 3 - Vazões e concentrações dos parâmetros medidos e estimados.

\begin{tabular}{|c|c|c|c|c|c|c|c|c|c|c|}
\hline \multirow{2}{*}{$\begin{array}{l}\text { Tributário/ } \\
\text { Lançamento }\end{array}$} & \multirow{2}{*}{ Ponto } & \multirow{2}{*}{ Data } & \multirow{2}{*}{$\begin{array}{c}\begin{array}{c}\text { Vazão } \\
\text { pontual }\end{array} \\
\left(\mathbf{m}^{3} / \mathbf{s}\right)\end{array}$} & \multirow{2}{*}{$\frac{\mathbf{T}}{\left({ }^{\circ} \mathrm{C}\right)}$} & OD & DBO & $\mathbf{N H}_{3}^{+}$ & $\mathrm{NO}_{3}^{-}$ & $\mathbf{P}_{\text {total }}$ & \multirow{2}{*}{$\frac{\text { E-coli }}{(\mathrm{NMP} / 100 \mathrm{~mL})}$} \\
\hline & & & & & \multicolumn{5}{|c|}{$(\mathrm{mg} / \mathrm{L})$} & \\
\hline \multirow{12}{*}{$\begin{array}{c}\text { Ribeirão } \\
\text { Salitre }\end{array}$} & \multirow{4}{*}{1} & Ago/17 & 0,30 & 17,7 & 6,53 & 7 & 0,308 & 0,11 & 0,050 & 0 \\
\hline & & Set/17 & 0,15 & 19,0 & 7,67 & 6 & 0,311 & 0,08 & 0,064 & 4 \\
\hline & & Nov/17 & 1,41 & 21,7 & 7,11 & 4 & 0,330 & 0,08 & 0,084 & 23 \\
\hline & & Dez/17 & 1,13 & 22,2 & 7,67 & 3 & 0,172 & 0,09 & 0,076 & 23 \\
\hline & \multirow{4}{*}{2} & Ago/17 & 0,65 & 17,8 & 6,53 & 6 & 0,283 & 0,10 & 0,229 & 23 \\
\hline & & Set/17 & 0,46 & 20,5 & 6,80 & 4 & 0,232 & 0,07 & 0,223 & 0 \\
\hline & & Nov/17 & 1,51 & 21,4 & 7,02 & 5 & 0,242 & 0,07 & 0,171 & 75 \\
\hline & & Dez/17 & 1,50 & 21,5 & 7,07 & 3 & 0,122 & 0,08 & 0,170 & 240 \\
\hline & \multirow{4}{*}{3} & Ago/17 & ---- & 17,8 & 7,07 & 6 & 0,311 & 0,28 & 0,250 & 15 \\
\hline & & Set/17 & $\begin{array}{ll}--- \\
\end{array}$ & 20,8 & 6,68 & 7 & 0,281 & 0,11 & 0,175 & 9 \\
\hline & & Nov/17 & $\begin{array}{ll}--- \\
\end{array}$ & 21,4 & 7,67 & 5 & 0,262 & 0,10 & 0,130 & 240 \\
\hline & & Dez/17 & ---- & 21,7 & 7,67 & 3 & 0,123 & 0,15 & 0,124 & 1100 \\
\hline \multirow{4}{*}{$\begin{array}{c}\text { Córrego } \\
\text { Bebedouro }\end{array}$} & \multirow{4}{*}{4} & Ago/17 & 0,32 & 17,9 & 6,53 & 4 & 0,240 & 0,07 & 0,573 & 23 \\
\hline & & Set/17 & 0,31 & 20,8 & 7,67 & 4 & 0,167 & 0,05 & 0,586 & 0 \\
\hline & & Nov/17 & 0,45 & 20,9 & 7,07 & 10 & 0,167 & 0,05 & 0,307 & 240 \\
\hline & & Dez/17 & 0,36 & 21,2 & 6,65 & 2 & 0,033 & 0,05 & 0,299 & 1100 \\
\hline \multirow{4}{*}{$\begin{array}{c}\text { Córrego } \\
\text { Areia }\end{array}$} & \multirow{4}{*}{5} & Ago/17 & 0,29 & 17,9 & 6,53 & 7 & 0,264 & 0,60 & 0,069 & 9 \\
\hline & & Set/17 & 0,18 & 21,1 & 6,97 & 8 & 0,140 & 0,20 & 0,084 & 15 \\
\hline & & Nov/17 & 0,41 & 21,3 & 6,97 & 4 & 0,220 & 0,22 & 0,091 & 1100 \\
\hline & & Dez/17 & 0,34 & 21,7 & 7,37 & 4 & 0,016 & 0,45 & 0,093 & 1100 \\
\hline \multirow{3}{*}{ ETE } & \multirow{3}{*}{---- } & Ago/17 & \multirow{3}{*}{0,0069} & \multirow{3}{*}{23} & \multirow{3}{*}{1,5} & \multirow{3}{*}{50} & \multirow{3}{*}{10} & \multirow{3}{*}{5} & \multirow{3}{*}{3,5} & \multirow{3}{*}{$10^{6}$} \\
\hline & & Set/17 & & & & & & & & \\
\hline & & Nov/17 & & & & & & & & \\
\hline \multirow{2}{*}{$\begin{array}{c}\text { Entradas } \\
\text { difusas } \\
\left(\mathbf{m}^{3} / \mathrm{s.m}\right) \\
\end{array}$} & \multirow{2}{*}{$\begin{array}{c}\text { Entre } \\
\text { pontos } \\
1 \text { e } 2 \\
\end{array}$} & Nov/17 & $2,63 * 10^{-5}$ & --- & 7 & 3 & 0,1 & 0,2 & 0,05 & --- \\
\hline & & Dez/17 & $2,14 * 10^{-5}$ & --- & 7 & 3 & 0,1 & 0,2 & 0,05 & --- \\
\hline \multirow{2}{*}{$\begin{array}{l}\text { Entradas } \\
\text { difusas } \\
\left(\mathbf{m}^{3} / \mathrm{s} . \mathrm{m}\right)\end{array}$} & \multirow{2}{*}{$\begin{array}{l}\text { Entre } \\
\text { pontos } \\
2 \text { e } 3\end{array}$} & Nov/17 & $2,80 * 10^{-5}$ & --- & 7 & 3 & 0,1 & 0,2 & 0,05 & --- \\
\hline & & Dez/17 & $2,28 * 10^{-5}$ & --- & 7 & 3 & 0,1 & 0,2 & 0,05 & --- \\
\hline
\end{tabular}



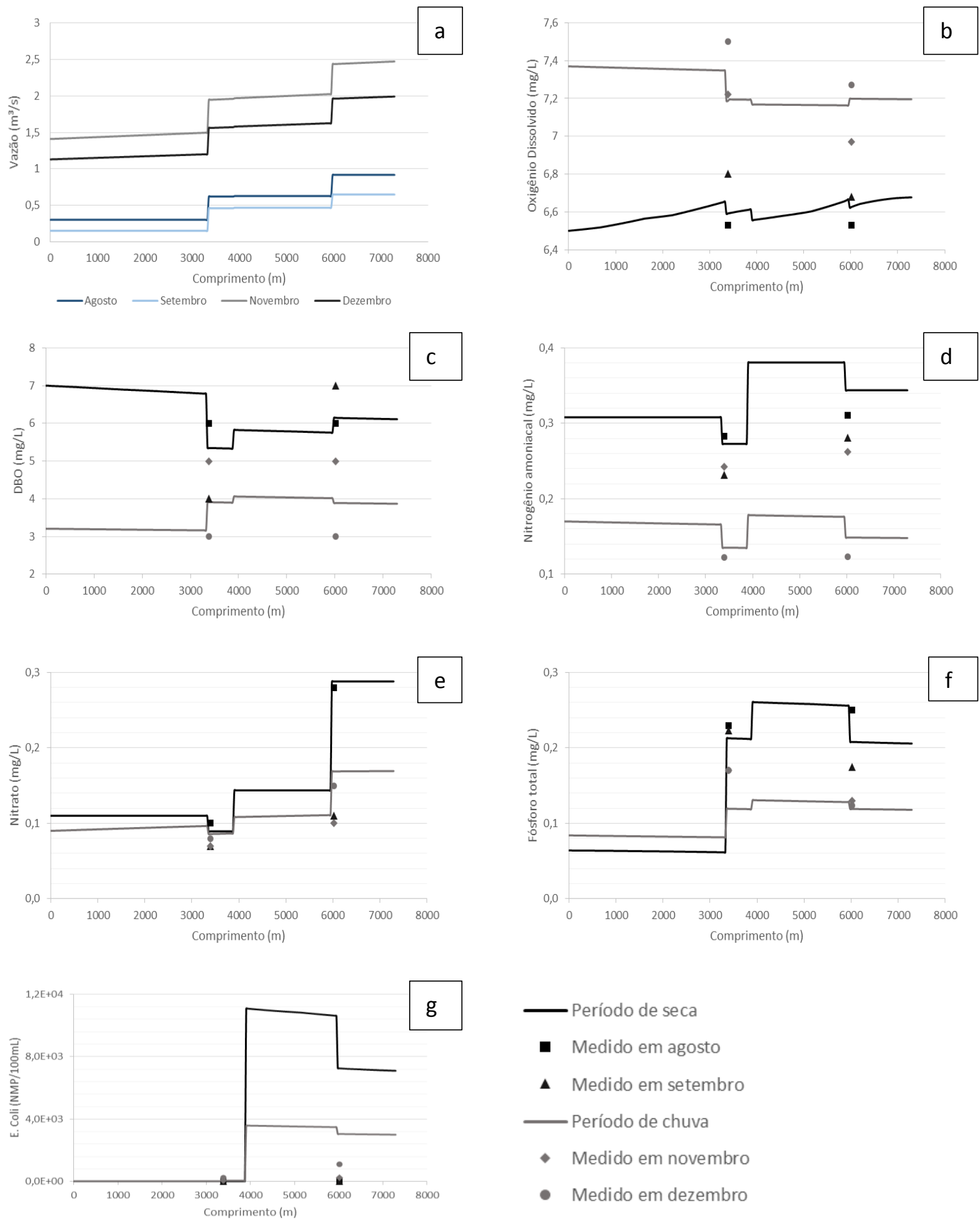

Figura 4 - a) Vazão, b) OD, c) DBO, d) nitrogênio amoniacal, e) nitrato, f) fósforo total e g) E.coli

Valores próximos foram obtidos por Fernandes (2016) (entre 0,4 a 0,9 $\mathrm{dia}^{-1}$ ), por Salla et al. (2014) (entre 0,2 a 0,4 $\mathrm{dia}^{-1}$ ), por Paula (2011) (entre 0,15 a $0,25 \mathrm{dia}^{-1}$ ) e por Tonon (2014) $\left(0,16 \mathrm{dia}^{-1}\right)$. O coeficiente de decaimento do fósforo total $\mathrm{k}_{\mathrm{P}}$ manteve-se entre 0,25 a 0,30 dia $^{-1}$ e se encontra dentro do intervalo apresentado por Von Sperling (2014), entre 0,20 a 0,30 $\mathrm{dia}^{-1}$, e por Bowie et al. (1985), entre 0,001 a $0,80 \mathrm{dia}^{-1}$. Outros estudos alcançaram valores próximos para $\mathrm{k}_{\mathrm{P}}$, tais como 0,01 a $0,8 \mathrm{dia}^{-1} \mathrm{em}$ Fernandes (2016), 0,01 dia $\mathrm{di}^{-1}$ em Salla et al. (2014) e Ferreira (2014), 0,2 a 0,3 dia $^{-1}$ em Paula (2011) e $0,7 \mathrm{dia}^{-1}$ em Tonon (2014).

De uma forma geral, a proximidade dos coeficientes calibrados com os de outros estudos se dá pela similaridade hidrológica (mesma ordem de grandeza para a vazão), pela similaridade na declividade de fundo e uso e ocupação do solo. 
Tabela 4 - Coeficientes calibrados.

\begin{tabular}{|c|c|c|c|c|}
\hline Coef. & Unid. & $\begin{array}{c}\text { Trecho no Rib. } \\
\text { Salitre } \\
\end{array}$ & $\begin{array}{c}\text { Período } \\
\text { estiagem }\end{array}$ & $\begin{array}{l}\text { Período } \\
\text { chuvoso } \\
\end{array}$ \\
\hline \multirow{4}{*}{$\mathbf{k}_{\mathbf{2}}$} & \multirow{4}{*}{$d^{-1}$} & Ponto 1 até ponto 2 & 0,74 & 38,86 \\
\hline & & Ponto 2 até ETE & 1,50 & 19,41 \\
\hline & & ETE até ponto 3 & 1,51 & 19,41 \\
\hline & & Ponto 3 até exutório & 0,50 & 57,04 \\
\hline \multirow{4}{*}{$\mathbf{K}_{\mathbf{d}}$} & \multirow{4}{*}{$d^{-1}$} & Ponto 1 até ponto 2 & 0,12 & 0,12 \\
\hline & & Ponto 2 até ETE & 0,13 & 0,12 \\
\hline & & ETE até ponto 3 & 0,15 & 0,18 \\
\hline & & Ponto 3 até exutório & 0,15 & 0,12 \\
\hline VSMo & $\mathbf{m} / \mathbf{d}$ & \multirow{6}{*}{ Ponto 1 até exutório } & 0,05 & 0,05 \\
\hline $\mathbf{K}_{\mathbf{a n}}$ & $\mathbf{d}^{-1}$ & & 0,15 & 0,20 \\
\hline$K_{n n}$ & $d^{-1}$ & & 0,20 & 0,50 \\
\hline $\mathbf{V}_{\text {sP }}$ & $\mathbf{m} / \mathbf{d}$ & & 0,02 & 0,02 \\
\hline $\mathbf{K}_{\mathbf{P}}$ & $d^{-1}$ & & 0,25 & 0,30 \\
\hline $\mathbf{K}_{\mathbf{b}}$ & $d^{-1}$ & & 1,00 & 1,00 \\
\hline
\end{tabular}

\section{Cenários analisados}

O foco dos cenários 1,2 e 3 foi avaliar o impacto do avanço da atividade de mineração na qualidade de água ao longo do todo o ribeirão do Salitre.

Já os cenários 4, 5 e 6 avaliaram o impacto do crescimento das atividades de agropecuária e
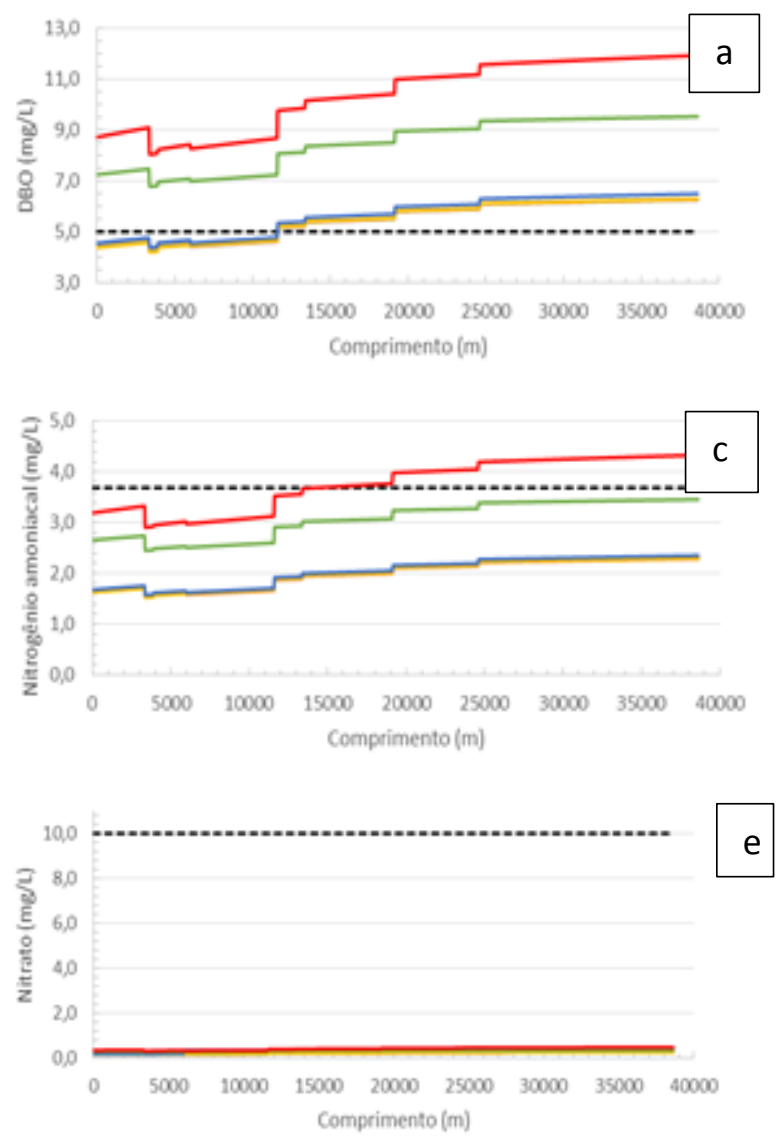

agricultura na qualidade de água no ribeirão.

A figura Erro! Fonte de referência não encontrada.5 apresenta os perfis de concentração dos parâmetros de qualidade em todos os cenários, além do limite de concentração definido pela Resolução CONAMA 357: 2005.
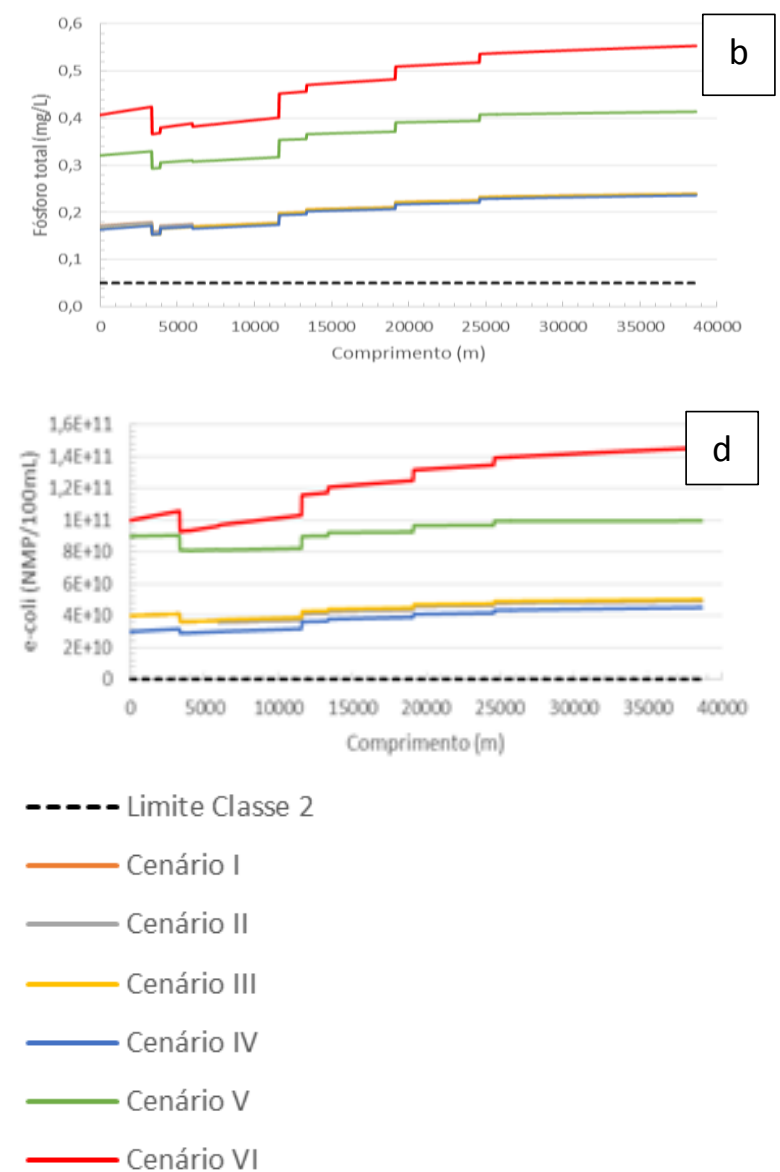

Figura 5 - Perfis de concentração dos parâmetros de qualidade e limite de concentração definido pela Resolução CONAMA 357:2005: a) DBO; b) fósforo total; c) nitrogênio amoniacal; d) E.coli; e) nitrato. 
Os perfis de concentração dos parâmetros ficaram praticamente sobrepostos para os cenários 1, 2 e 3 (Figura 5). Esta sobreposição permite concluir que o avanço gradual da área de mineração pouco influenciou na qualidade de água do ribeirão.

A concentração máxima de DBO definida para o tipo de classe do Ribeirão do Salitre é de $5 \mathrm{mg} / \mathrm{L}$ (classe 2). Entretanto, com as simulações, os cenários avaliados apresentaram concentrações superiores a este valor. Nos cenários 1,2, 3 e 4, até o comprimento $11,5 \mathrm{~km}$, as concentrações de DBO apresentaram-se abaixo do máximo recomendado, visto que na quilometragem 11,5 ocorre o lançamento pontual da sub-bacia 5. A partir dessa distância, as concentrações apresentaram valores superiores a $5 \mathrm{mg} / \mathrm{L}$.

Apenas para o cenário 6, após a distância de 14,7 km, a concentração de nitrogênio amoniacal supera o máximo permitido de $3,7 \mathrm{mg} / \mathrm{L}$ (conforme Resolução CONAMA 357:2005), esta concentração ocorre entre as sub-bacias 5 e 6 quando a área da sub-bacia analisada é de 400 $\mathrm{km}^{2}$. A partir dessa distância, deve-se avaliar as consequências dessas concentrações, uma vez que amônia é tóxica para a fauna aquática. A concentração de nitrato para os cenários analisados apresentou valores inferiores ao limite estabelecido para esse nutriente em função da classe do rio, o qual é de $10 \mathrm{mg} / \mathrm{L}$. A maior concentração foi de $0,488 \mathrm{mg} / \mathrm{L}$ que ocorre no final do trecho analisado do cenário 6 .

De acordo com a Resolução CONAMA 357:2005, a concentração de fósforo total deve ser de até $0,050 \mathrm{mg} / \mathrm{L}$. Nos cenários analisados a concentração de fósforo superou o limite estabelecido, variando de 0,152 a $0,554 \mathrm{mg} / \mathrm{L}$.

A concentração de E.coli nas curvas de concentração dos cenários apresenta-se valores superiores ao limite da classe do rio, que é de $1000 \mathrm{NMP} / 100 \mathrm{~mL}$, sendo o menor valor de $2,90 \times 10^{10} \mathrm{NMP} / 100 \mathrm{~mL}$. A elevada concentração de E. coli está relacionada ao coeficiente de geração de cargas deste parâmetro utilizados pelo programa MQUAL (Tabela 1).

\section{CONCLUSÃO}

A calibração dos coeficientes de reações bioquímicas apresentou ajustes satisfatórios entre os valores medidos e simulados para os parâmetros demanda bioquímica de oxigênio, nitrogênio amoniacal, nitrato e fósforo total. Uma forma de otimizar a calibração do parâmetro E-coli é monitorar a qualidade de efluente lançado pela ETE de Salitre de Minas.

Com a expansão da atividade de mineração, e mantidas as áreas atuais ocupadas para agricultura e pecuária, a qualidade da água no ribeirão do Salitre não será prejudicada. É importante salientar que o programa MQUAL não especifica o tipo de atividade industrial utilizados na estimativa da carga de nutrientes gerada.

Se toda a sub-bacia do Ribeirão do Salitre substituir as atividades agropecuárias por agricultura, a qualidade da água será prejudicada, principalmente com relação aos parâmetros DBO, nitrogênio e fósforo.

Recomenda-se, em novas pesquisas, a verificação dos coeficientes em atividades industriais de mineração e o contínuo monitoramento da área, visto que a região analisada apresenta transformação no uso e ocupação do solo, bem como aumentar o período de coleta de amostras de água, o que possibilitará validar a modelo de qualidade da água no ribeirão do Salitre.

\section{REFERÊNCIAS}

ASSOCIAÇÃO BRASILEIRA DE NORMAS TÉCNICAS. NBR 9898: Preservação e técnicas de amostragem de efluentes líquidos e corpos receptores. Rio de Janeiro, 1987. 22 p.

BOWIE, L.G.; MILLS, W.B.; PORCELLA, D.B.; CAMPBEL, L.C.; PAGENKOPF, J.R.; RUPP, G.L.; JOHNSON, K.M.; CHAN, R.W.H.; GHERINI, S.A.; CHAMBERLIN C.E. Rates constants and kinetics formulations in surface water quality modeling. 2 ed. EPA, 1985.

BRASIL. Lei n. 12.651, de 25 de maio de 2012. Dispõe sobre a proteção da vegetação nativa; altera as Leis nos 6.938, de 31 de agosto de 1981, 9.393, de 19 de dezembro de 1996, e 11.428, de 22 de dezembro de 2006; revoga as Leis nos 4.771, de 15 de setembro de 1965, e 7.754, de 14 de abril de 1989, e a Medida Provisória no 2.166-67, de 24 de agosto de 2001; e dá outras providências. Código Florestal. Brasília, maio. 2012.

BRASIL. Resolução n. 357, de 11 de mar. de 2005. Dispõe sobre a classificação dos corpos de água e diretrizes ambientais para o seu enquadramento, bem como estabelece as condições e padrões de lançamento de efluentes, e dá outras providências. CONAMA 357/05, p. 58-63, mar. 2005.

CBH ARAGUARI. CBH Araguari. Disp. em: <https://www.cbharaguari.org.br>. Acesso em: 14 set. 2017.

CLIMATE-DATA.ORG. Disp. em: <https://pt.climatedata.org/location/24991/>. Acesso em: 17 nov. 2017.

CUNHA, M.P. Migração e urbanização no Brasil: alguns desafios metodológicos para análise. São Paulo em perspectiva, São Paulo, v. 19, n. 4, 2005

ESTADO DE SÃO PAULO. Secretaria de Saneamento e 
Recursos Hídricos. MQUAL. Version 1.6. São Paulo. 2016. $100 \mathrm{CD}-\mathrm{ROM}$.

FARIA, F.C. \& JORDÃO, L.F.A. Resumo Executivo do Plano de Recursos Hídricos da Bacia do rio Araguari. Monte Carmelo: Monte Plan Ltda, 2011. 120 p. Disp. em: <https://www.cbharaguari.org.br/uploads/1_o_comite/3_legisl acao/1_plano_diretor_bacia/17_resumo_executivo_pdrh_arag uari.pdf>. Acesso em: 25 set. 2017.

FERNANDES, L.E. Ajuste de coeficientes integrantes de processos físicos e bioquímicos na autodepuração em curso de médio porte. Uberlândia, 2016. 145 p. Dissertação (Mestrado em Engenharia Civil) - Faculdade de Engenharia Civil, Universidade Federal de Uberlândia.

FERREIRA, A.F. Capacidade de autodepuração nos cursos médio e baixo do rio Uberaba, UPGRH-GD8. Uberlândia, 2014. 134 p. Dissertação (Mestrado em Engenharia Civil) Faculdade de Engenharia Civil, Universidade Federal de Uberlândia.

FORMENTINI, T.A. Coeficientes de desoxigenação e de reaeração superficial em trechos do rio Vacacaí Mirim. Santa Maria, 2010. 91p. Dissertação (Mestrado em Engenharia Civil) - Programa de Pós-Graduação em Engenharia Civil. Universidade Federal de Santa Maria.

IBGE. IBGE/ Brasil em síntese. Disponível em: <http://cidades.ibge.gov.br>. Acesso em: 31 mar. 2018.

ISHERWOOD, K. F. Mineral Fertilizer Use and the Environment. Paris: International Fertilizer Industry Association, 2010. 63 p. Disp. em: <http://www.anda.org.br/ multimidia/fertilizantes_meio_ambiente.pdf $>$. Acesso em: 04 set. 2017.

JHUNIOR, H.S. Otimização do aproveitamento hídrico superficial da bacia hidrográfica do rio Araguari, Triângulo Mineiro. Uberlândia, 2017. 117 p. Dissertação (Metrado em Engenharia Civil) - Faculdade de Engenharia Civil, Universidade Federal de Uberlândia.

MAGALHÃES, A.A.B.; SALLA, M.R.; FILHO, J.E.A. Manual do Usuário QUALI-TOOL: Uma ferramenta gráficainterativa para simulação da qualidade da água em ambientes lóticos. Uberlândia, 36 p., 2017a.

MAGALHÃES, A.A.B.; SALLA, M.R.; FILHO, J.E.A. QUALITOOL. Version 1. Uberlândia. 2017. Disp. em: $<$ http://labsanufu.wixsite.com/site/copia-extensao>. Acesso em: 01 set. $2017 \mathrm{~b}$.

NUNES, D.G. Modelagem da autodepuração e qualidade da água do rio Turvo Sujo. Viçosa, 2008. 118 p. Dissertação (Mestrado em Engenharia Agrícola), Universidade Federal de Viçosa.

OLIVEIRA FILHO, A.A. Modelagem da qualidade da água do rio Poti. Fortaleza, 2014. 93p. Dissertação (Mestrado em Engenharia Civil), Universidade Federal do Ceará, Fortaleza.

OLIVEIRA, F.G.C. \& SARDINHA, D.S. Avaliação das cargas difusas na bacia do córrego da Ariranha, Poços de Caldas - MG, utilizando o modelo MQUAL 1.5. XII Congresso Nacional de Meio Ambiente de Poços de Caldas, Poços de Caldas - MG, maio. 2014
PAREDES-ARQUIOLA, J.; ANDREU-ALVAREZ, J.; MARTIN-MONERRIS, M.; SOLERA, A. Water quantity and quality models applied to the Jucar river basin, Spain. Journal of water resources planning and management, v.24, n.11, p. 2759-2779, 2010.

PAULA, L.M. Avaliação da qualidade da água e autodepuração do rio Jordão, Araguari (MG). Uberlândia, 2011. 196 p. Dissertação (Mestrado em Engenharia Civil) Faculdade de Engenharia Civil, Universidade Federal de Uberlândia.

PMP. Prefeitura Municipal de Patrocínio: Informações sobre o município. Disponível em: <http://www.patrocinio.mg. gov.br/pm/index.php/municipio/informacoes-sobre-omunicipio >. Acesso em: 25 set. 2017.

SALLA, M.R.; PAREDES-ARQUIOLA, J.; SOLERA, A.; ALVAREZ, J.A.; PEREIRA, C.E.; ALAMY FILHO, J.E.; OLIVEIRA, A.L. Sistema de Suporte à Decisão em Recursos Hídricos na Bacia Hidrográfica do rio Uberabinha, Minas Gerais. Revista Brasileira de Recursos Hídricos, [S.L], v. 19, n. 1, p. 189-204, 2014.

SANÁGUA, Análises Químicas e Ambientais. O Histórico dos Agrotóxicos: Os Agrotóxicos e a Indústria Química. Disponível em: 〈http://sanagua.com.br〉. Acesso em: 22 ago. 2017.

SMA, Secretaria de Estado do Meio Ambiente Estado de São Paulo. Elaboração do Plano de Desenvolvimento e Proteção Ambiental da Bacia Hidrográfica do Reservatório Billings. São Paulo, 274 p., 2010.

SUPRAM-TM/AP, Superintendência Regional de Regularização Ambiental. Licença de Instalação Corretiva (LIC): Licenciamento Ambiental PA COPAM: 17414/2007/007/2015. Uberlândia: Governo do Estado de Minas Gerais, 106 p., 2015.

TONON, K. Modelagem da qualidade da água utilizando os modelos Streeter-Phelps e QUAL-UFMG na bacia do rio Lambari - Poços de Caldas (MG). Alfenas, 2014. 168p. Dissertação (Mestrado em Ciências e Engenharia Ambiental), Universidade Federal de Alfenas.

VON SPERLING, M. Estudos e modelagem da qualidade da água de rios. 7 ed. Belo Horizonte: UFMG, 558 p., 2005.

VON SPERLING, M. Introdução à qualidade das águas e ao tratamento de esgoto. 4 ed. Belo Horizonte: UFMG, 452 p., 2014. 